\title{
Citizen Science in Higher Education
}

SPECIAL COLLECTION: CITIZEN SCIENCE IN HIGHER EDUCATION

\section{COLLEEN HITCHCOCK (1)}

HEATHER VANCE-CHALCRAFT (1)

MARIA ARISTEIDOU (1)

*Author affiliations can be found in the back matter of this article

\section{ABSTRACT}

Editorial for the special collection: Citizen Science in Higher Education.

CORRESPONDING AUTHOR:

\section{Colleen Hitchcock}

Brandeis University, US hitchcock@brandeis.edu

\section{KEYWORDS:}

citizen science; higher education; curricular; co-curricular; broadening participation

TO CITE THIS ARTICLE:

Hitchcock, C, Vance-Chalcraft, H and Aristeidou, M. 2021. Citizen Science in Higher Education. Citizen Science: Theory and Practice, 6(1): 22, pp. 1-4. DOI: https://doi.org/10.5334/cstp.467 
Considerable anecdotal evidence exists to show widespread usage of citizen science in higher education settings, but the published literature on its use is limited (VanceChalcraft et al. in press). In this special collection, we strive to strengthen the growing body of literature on the use of citizen science with higher education students by sharing examples of citizen science integration into courses, the research around the resulting educational outcomes, and the success and challenges of citizen science in the higher education landscape. In our approach, we follow Cooper et al. (2021) in which the term citizen science is being used inclusively to describe the variety of projects and ways in which the public is involved in research. We hope this collection spurs an increase in dialogue and in idea exchanges among stakeholders (project developers, project evaluators, data end-users, course instructors, students, and the broader higher education community).

Integrating citizen science into higher education has the potential to provide numerous benefits to students. It has been proposed that citizen science increases student engagement, provides opportunities to engage students in authentic research, highlights the applied relevance of course activities, introduces students to the principles of research, provides access to data sets, and creates pathways for inclusion of science in students' lives outside of courses (NASEM 2018). These benefits have been documented more rigorously in informal learning environments, though, with few studies from formal postsecondary settings (NASEM 2018). This special collection helps to fill that gap, especially with respect to integration into higher education.

Just as the potential benefits of citizen science integration are numerous, the ways in which this integration can occur seem limitless. Thus, instructors interested in citizen science may feel overwhelmed by the possibilities and desire concrete examples of how others have successfully implemented citizen science with students (VanceChalcraft et al. in press). This special collection provides a variety of case studies in multiple course types, course sizes, student audiences, and academic levels. Included articles explore the ways both online and field-based citizen science can be integrated into higher education.

\section{IN THIS COLLECTION}

The contributions in this special collection share authors' experiences with citizen science as a tool for teaching, learning, and connecting to the natural world. Readers will come away with ideas of how students are engaged, perceive citizen science, and feel included. Several papers explore different tools for using citizen science, including those for conducting citizen science and for evaluating participant experiences. Exploration of data quality concerns and efforts to enhance data literacy are evident throughout the papers. Finally, the timing of the special collection reflects how the COVID-19 pandemic has shaped citizen science practices in higher education.

Many of the papers included here involve the goal of improved student learning and skills acquisition through citizen science. Golumbic and Motion find enhanced student knowledge of course content and the nature and process of science when students are exposed to authentic research in the form of citizen science in a chemistry laboratory course. Lichti et al. examine the data literacy and scientific writing skills of their students after completing a research project using openly available citizen science data and conclude that students could gain research skills through their efforts, even in a remote learning setting. Students in the Paradise and Bartkovich study gained biodiversity literacy skills by using BugGuide, an online collection of North American bug photos curated by naturalists, in addition to making a traditional insect collection in an entomology course. Vance-Chalcraft et al. assess knowledge related to citizen science and ecology, as well as the nature and process of science, in more than 1,200 students. They find that students made the largest knowledge gains in areas most related to the topic of the citizen science project (e.g., in this case, arthropod identification) rather than general conceptual gains about the process of science (e.g., interpreting data figures).

In addition to the knowledge and skills students gained through citizen science, multiple papers explore the potential of citizen science to engage students and to change their perceptions. Smith et al. describe how engaging students in citizen science activities resulted in an increased interest in science, and in learning and doing science. They suggest that citizen science activities should incorporate choice that accommodates diverse student interests and motivations. Golumbic and Motion find that students displayed increased levels of motivation when laboratory experiences included a citizen science approach. Vance-Chalcraft et al. analyze student reflection data from nearly 900 students to determine their perceptions of citizen science. After a modest exposure to Caterpillars Count!, a citizen science project researching arthropod seasonality and abundance, students identified citizen science as being an efficient way to collect large amounts of data, as well as producing benefits for the students, the environment, and the community. One of the reported benefits to students was increased enjoyment and engagement. Citizen science participation as a student may even influence scientific engagement after a course ends. Hitchcock et al. highlight student persistence doing citizen science after courses end by examining continued student use of iNaturalist, a global social network for biodiversity observation, and report that 
iNaturalist was effective at increasing student engagement and curiosity. Bedell and Gates examine how the content focus of citizen science impacts students' attitudes toward future participation. Using survey data from nearly 3,000 students who are pursuing a degree in a discipline outside of science, they find that the general content of citizen science projects (e.g., microbiology, ecology) was less influential on student attitudes toward future citizen science participation than student choice or features of individual projects.

Connecting students with the natural world and not just to science research is another theme present throughout the collection regardless of whether the work was virtual or field-based. Paradise and Bartkovich share a semesterlong example of building traditional and virtual insect collections with students. They use formative assessment to monitor ongoing learning, summative assessment to evaluate learning at the end of the semester, and student surveys to examine the impact of citizen science integration. Litchi et al. got students outdoors through engagement with Budburst, a website that hosts projects that address ecological challenges. Instructors provided students with a research question; students collected data and compared them against data from previous years. The output from this exercise was a scientific paper, which was assessed through a rubric designed to evaluate students' research skills such as developing predicting statements and graphs, and reviewing their methods and findings. The Caterpillars Count! project used by Vance-Chalcraft et al. engages students directly in fieldwork, as do the several papers that use iNaturalist (e.g.,

\section{Stevenson et al., Hitchcock et al., Smith et al.).}

The perspectives of participants and the sense of inclusion for those involved are additional ideas underlined by several authors. Johns et al. take a cross-university perspective in examining students' sense of belonging in science after having done citizen science. Their work is not restricted to either curricular or co-curricular uses of citizen science. They conclude that citizen science could serve as a valuable approach to broadening the engagement of historically marginalized groups in STEM. Aristeidou et al. bring an understanding of educators' perceptions through the engagement of post-graduate teachers in coursebased citizen science. They suggest their work could help design activities that attract and support educators in integrating citizen science in their own classroom activities. The case study of Dunbar-Wallis et al. illustrates an example of engagement with community college students as professional development and to gain research skills before transferring to a four-year institution. The majority of community college students who transferred to four-year institutions "communicated feelings of increased comfort engaging in fieldwork, greater confidence in the transition to university life, and the development of research selfefficacy" after participating in this experience.
Several papers focus on tools, highlighting the functionality of, design of, or evaluation of tools to facilitate citizen science activities and engagement in higher education courses. Dunbar-Wallis et al. describe undergraduate students' process to build a mobile phone application designed for collecting and visualizing data in real time via an interactive map. The application was tested with community members in large data-collection events called "Apple Blitzes," and the participants provided the developers with their feedback via a qualitative survey. The work of Bedell and Gates highlights the need for project design features that best encourage future participation. Common to a number of papers is the use of the tool iNaturalist. Instructors considering using iNaturalist will benefit from examining these papers, which vary in their approaches to including the tool. Smith et al. describe how coursebased citizen science activities using iNaturalist resulted in a slight increase in interest in nature, and self-efficacy for environmental action; whereas Stevenson et al. illustrate iNaturalist use in a co-curricular bioblitz event. Hitchcock et al. present three case studies from diverse course types that use iNaturalist to improve student bioliteracy, engagement in biodiscovery, and data literacy. The authors of these case studies hope to inspire others to adopt the tool by sharing the rationale for using iNaturalist, how iNaturalist compliments their courses, and the outputs of students' iNaturalist use. Overall, the authors stress the importance of platforms and tools as means of delivering citizen science activities in the higher education classroom, and showcase how different designs can contribute to a variety of learning and engagement outcomes.

Student concerns about data quality or tests of quality from student-collected data were considered in multiple papers. Aristeidou et al. find that post-graduate teachers recognize the potential of citizen science for learning but are skeptical about the role of experts and the quality of data. Postgraduate teachers acknowledge that technologies are beingusedtosupportdatavalidation, buttheystillquestioned whether non-academics could contribute real science data. Stevenson et al., however, examine the quality of data collected in a co-curricular bioblitz using iNaturalist, and demonstrate that with some training, observations provided by these first-time users are quite useful.

With the timing of this special collection during the ongoing global COVID-19 pandemic, several authors acknowledge how their work was impacted by the needs of the pandemic or how the pandemic influenced their own motivations for inclusion of citizen science. Dunbar-Wallis et al., Litchi et al., Hitchcock et al., and Smith et al., all illustrate how the previous use of citizen science in their courses facilitated their course pivots from in-person to remote learning; whereas Bedell and Gates and Golumbic and Motion note that the pandemic highlights the need 
for more authentic research, such as citizen science, to be included in courses to improve scientific literacy.

In summary, this special collection demonstrates many ways in which the addition of citizen science to higher education courses and to co-curricular activities benefits students while contributing useful scientific data and broadening participation in citizen science. The diverse ways citizen science is being incorporated into higher education highlight a powerful strength of this approach-its flexibility and adaptability. As events such as global pandemics and extreme weather disrupt traditional learning environments, citizen science has provided valuable alternative pathways to learning and engagement. In embracing citizen science, institutions have also embraced technology, to become more open and engaged with their surrounding (or distant) communities. In some instances, meaningful collaborations have blossomed between students, instructors, scientists, citizen science project staff, and interested members of the public. Thus, the inclusion of citizen science in higher education represents a valuable way to increase student engagement with the world beyond the confines of a single semester.

\section{ACKNOWLEDGEMENTS}

We appreciate all the authors and reviews whose contributions helped bring this special collection into being. The publication of this special collection was partially funded by the National Science Foundation RCN-UBE award \#1919928 to HVC.

\section{COMPETING INTERESTS}

The authors have no competing interests to declare.

\section{AUTHOR AFFILIATIONS}

Colleen Hitchcock (D) orcid.org/0000-0002-3413-8951

Brandeis University, US

Heather Vance-Chalcraft (D) orcid.org/0000-0002-7230-1342

East Carolina University, US

Maria Aristeidou (D) orcid.org/0000-0001-5877-7267

The Open University, GB

\section{REFERENCES}

Cooper, CB, Hawn, CL, Larson, LR, Parrish, JK, Bowser, G, Cavalier, D, Dunn, RR, Haklay, M, Gupta, KK, Jelks, NTO, Johnson, VA, Katti, M, Leggett, Z, Wilson, OR and Wilson, S. 2021. Inclusion in citizen science: The conundrum of rebranding. Science, 372(6549): 1386-1388. DOI: https://doi. org/10.1126/science.abi6487

[NASEM] National Academies of Sciences, Engineering, and

Medicine. 2018. Learning Through Citizen Science: Enhancing Opportunities by Design. Washington, DC: The National Academies Press. DOI: https://doi.org/10.17226/25183

Vance-Chalcraft, HD, Hurlbert, AH, Styrsky, JN, Gates, TA, Bowser, G, Hitchcock, C, Reyes, MA and Cooper, CB. In press. Citizen Science in Post-Secondary Education: Current Practices and Knowledge Gaps. BioScience. DOI: https://doi. org/10.1093/biosci/biab125

\section{TO CITE THIS ARTICLE:}

Hitchcock, C, Vance-Chalcraft, H and Aristeidou, M. 2021. Citizen Science in Higher Education. Citizen Science: Theory and Practice, 6(1): 22, pp. 1-4. DOI: https://doi.org/10.5334/cstp.467

Submitted: 16 September 2021 Accepted: 29 September 2021 Published: 01 December 2021

\section{COPYRIGHT:}

(C) 2021 The Author(s). This is an open-access article distributed under the terms of the Creative Commons Attribution 4.0 International License (CC-BY 4.0), which permits unrestricted use, distribution, and reproduction in any medium, provided the original author and source are credited. See http://creativecommons.org/licenses/by/4.0/.

Citizen Science: Theory and Practice is a peer-reviewed open access journal published by Ubiquity Press.

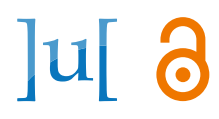

